\title{
Um relato do projeto de extensão "construindo ambientes saudáveis": entendendo as diferentes casas que nos abrigam.
}

An overview of the extension project "Building Healthy Environments": understanding the different homes that shelter us.

Un relato sobre el proyecto de extensión "Construyendo Ambientes Saludables": Comprendiendo las diferentes casas que nos abrigan.

Soraya Fleischer ${ }^{1}$

Fernando Carneiro ${ }^{2}$

\section{PREÂMBULO ${ }^{3}$}

No mês de agosto de 2008, a Universidade de Brasília deu início a mais um campus, dentro da perspectiva multicêntrica que vem sendo promovida em várias universidades federais brasileiras na década atual. Além de contar com dezenas de cursos, institutos e infra-estrutura no campus Darcy Ribeiro, na Asa Norte, e na Faculdade de Planaltina, na cidade homônima, a partir de então, a UnB passava a se desenvolver também na cidade de Ceilândia, maior região administrativa localizada dentro do Distrito Federal, e, logo em seguida, na cidade do Gama.

A Faculdade da Ceilândia, conhecida como FCE, abrange, até o momento, cinco cursos de graduação, Terapia Ocupacional, Enfermagem, Saúde Coletiva, Fisioterapia e Farmácia, e, a cada fase vestibular, 240 novos estudantes são

\footnotetext{
${ }^{1}$ Professora do Departamento de Antropologia/UnB. sorayafleischer@hotmail.com

${ }^{2}$ Professor de Saúde, Ambiente e Trabalho do Campus Ceilândia/UnB.fernandocarneiro.brasilia@gmail.com

${ }^{3}$ Este relato foi apenas escrito por estes dois autores. A história do projeto e seu desenvolvimento são frutos de muitas mãos e mentes. O projeto "Construindo Ambientes Saudáveis" é composto atualmente pelos seguintes participantes, em ordem alfabética: Adriana Modesto, Antônio da Silva Matos, Camila Mariah dos Santos, Fernando Carneiro Giuvanna de Sousa Silva, Hellen Delchova, Hernandes Assis de Freitas, Joaquim Pedro, Luciana Passos, Luciano José da Silva, Lusmair Brito, Margô Gomes de Oliveira Karnikowski, Mariana Torres Maximo,Micheli Pereira, Natalia de Paula Oliveira, Nathalie Azevedo, Rubia Maria Mendes do Nascimento, Talita Maleski, Thiara Café. No decorrer do ano de 2009, o projeto contou com outras pessoas: Anna Lídia e Sandra Regina. Para entrar em contato com o projeto: fernandocarneiro.brasilia@gmail.com.
}

Tempus. Actas em Saúde Coletiva, vol. 4, n. 4, p. 149-157. 2009. 
recebidos. Até o momento, a FCE conta com 50 professores, e chegará a um quadro docente completo de 140 mestres e doutores. Inicialmente, a Faculdade se instalou por alguns meses no prédio do Núcleo de Práticas Jurídicas da Faculdade de Direito, originalmente destinado (desde os anos 1980) às atividades de extensão da UnB. Depois, ainda sob regime provisório, a FCE foi transferida para uma parte do Centro de Ensino Médio n. 4 (doravante, CEM 4), localizado na Guariroba, bairro da parte Sul da Ceilândia. Neste espaço, a FCE conta com salas de aula, laboratórios, uma pequena biblioteca, um centro administrativo, uma lanchonete e um estacionamento. A previsão é que a FCE ocupe ainda em 2010 uma área definitiva e especialmente construída para tal, entre os limites da Ceilândia e Samambaia.

Assim que a FCE foi instalada, ainda que em espaços provisórios, várias atividades e tarefas têm sido necessárias para consolidar a instituição. De imediato, os currículos dos cinco cursos, acervo da biblioteca, regulamentação de estágios e práticas laboratoriais, formação de comissões e grupos de trabalho específicos, elaboração dos editais para a contratação dos novos docentes foram discutidos e elaborados pela equipe multidisciplinar e multisetorial de estudantes, professores e técnicos administrativos da FCE. Uma vez encaminhada essa etapa inicial, iniciativas de pesquisa e extensão começaram a ser idealizadas pelo corpo acadêmico da FCE.

Este relato tem por objetivo apresentar o primeiro projeto de extensão iniciado na FCE, "Formação comunitária para ações de promoção da saúde e da qualidade de vida - Construindo Ambientes Saudáveis". Embora tenha sido escrito pelos seus coordenadores, a memória reflexiva sobre esse projeto é coletiva e se beneficiará aqui de comentários críticos esboçados por vários de seus membros. O intuito é produzir um relato polifônico, preservando a atmosfera democrática, colegiada e diversificada que tem sido idealizada pelo projeto.

\section{OS PRIMEIROS PASSOS DO PROJETO}

No início de 2009, no período de férias letivas, um grupo de professores/as começou a se reunir para compartilhar suas concepções sobre a idéia de "extensão". Foi feito um trabalho preliminar e preparatório para esse ciclo de reuniões. Era preciso conhecer um pouco da história da extensão na UnB e começou-se pelas revistas Participação, publicadas desde 1997, pelo Decanato de Extensão. Alguns artigos foram escolhidos, dentre os 14 números pesquisados, para serem lidos previamente pelos participantes destas reuniões.

Tempus. Actas em Saúde Coletiva, vol. 4, n. 4, p. 149-157. 2009. 
Além disso, professores reconhecidos pela sua experiência com a extensão universitária foram convidados a compartilhar seus aprendizados com o grupo.

Estas reuniões, ainda no mês de janeiro de 2009, permitiram que o grupo amadurecesse uma concepção de extensão. Esse foi o primeiro desafio enfrentado, justamente questionar concepções um pouco desatualizadas (mas ainda em uso) para "extensão" e também lhe constituir um espaço mais legitimado dentro do ambiente acadêmico. Um dos avanços foi perceber a limitação de se continuar a entender a extensão como integrante de um suposto "tripé", ao lado da pesquisa e do ensino. Esta configuração tripartite contribui, em alguma medida, para que estas vocações da universidade se mantenham separadas. O grupo caminhava para um entendimento da extensão como parte indissociável das atividades dentro de sala de aula, laboratórios e outros espaços de pesquisa. Tudo deveria, idealmente, caminhar em comunhão constante.

Uma vez burilado o conceito, avançou-se para estabelecer linhas de ação. Como o grupo reunia professores/as de várias áreas disciplinares e com vários interesses de pesquisa, era preciso encontrar um eixo temático que acolhesse essas trajetórias profissionais. Acordou-se que duas principais idéias precisavam ser contempladas: a "saúde" como a primeira missão acadêmica da FCE e a relação imediata com a Ceilândia, cidade-anfitriã da FCE. Optou-se, então, por pensar numa categoria abrangente o suficiente para abrigar os interesses, experiências e expectativas dos/as participantes do grupo. Chegou-se a idéia de "ambientes saudáveis" como a meta extensionista do projeto. "Ambientes" não se restringiriam à base biômica ou ecológica de um espaço; ao contrário, pretendeu-se incluir várias possibilidades de existência dentro dessa categoria. Era preciso incluir diferentes acepções de "ambiente", como espaços físicos, atmosferas de trabalho, relações sociais, instituições como hospitais e creches, atores como movimentos sociais e lideranças comunitárias etc. Batizou-se o projeto como "Formação comunitária para ações de promoção da saúde e da qualidade de vida - construindo ambientes saudáveis" ou, para abreviar, "Construindo Ambientes Saudáveis". E, mais recentemente, o projeto tem sido conhecido com o sugestivo nome de "CASA"(4)4

\footnotetext{
${ }^{4}$ (4)Esse projeto é atualmente apoiado pelo Decanato de Extensão da UnB (Edital PIBEX, 2008); Núcleo da Agenda Ambiental (Edital da Agenda Ambiental da UnB) e Ministério da Educação (Edital PROEXT 2009).
}

Tempus. Actas em Saúde Coletiva, vol. 4, n. 4, p. 149-157. 2009. 
Se no início, isto é, nas reuniões preliminares durante o quente verão de 2009, contou-se com os/as estudantes que representavam o quadro discente, no momento em que o projeto começou a ganhar corpo, na forma de conceito, eixo temático e nome, abriu-se a iniciativa para o interesse de mais estudantes. Uma chamada pública foi realizada, apresentando os principais (e em permanente construção) objetivos do projeto. Um grupo com, mais ou menos, 15 estudantes, dos cinco cursos da FCE, apareceram na primeira reunião. Sua trajetória e expectativas em relação ao projeto foram socializadas. E o primeiro passo foi traduzir o conceito do projeto em linhas de ação mais concretas e visualizáveis.

\section{OS QUATRO EIXOS DO PROJETO}

Estudantes e professores/as, em sucessivas reuniões, estabeleceram que "Construindo ambientes saudáveis" contaria com quatro eixos de trabalho.

O primeiro eixo tem como objetivo conhecer, contatar e convidar movimentos sociais, organizações não governamentais, associações e lideranças comunitárias da Ceilândia para conhecer o projeto e somar esforços nas discussões sobre o mesmo. Não se pretende atrair parceiros e interlocutores apenas do movimento ambientalista, por exemplo. Como dito acima, "ambientes saudáveis" podem ser discutidos e planejados por grupos de jovens, historiadores e anciãos respeitados, representantes do movimento de saúde popular, grafiteiros e artistas etc. Cada novo contato é incorporado num banco de dados do projeto e, mais do que isso, são encaminhados convites para que participem das atividades do projeto e também da universidade como um todo e estimula-se que também façam propostas de atividades para incrementar 0 projeto. Esse diálogo recíproco e espelhado tem sido fundamental. Até agora, vários grupos, entidades e lideranças foram conhecidas e têm participado, de forma um pouco intermitente, do projeto. Podemos destacar algumas parcerias chaves estabelecidas com a comunidade, que mereceram encontros específicos e um convite a participar ativamente do projeto, como o Centro Paulo Freire (CEPAFRE) que já alfabetizou mais de 20.000 pessoas em Ceilândia; o Projeto CASA BRASIL (UnB/DEX/NPJ); o Movimento pró-Universidade Pública (MOPUC), que já luta há mais de 20 anos por uma universidade pública em Ceilândia, e o CEM 4, parceiro que abriga nossa universidade, ou seja, nossa atual casa.

O segundo eixo criou um Cine Clube. Idealmente, as sessões acontecem a cada mês, no auditório do Centro de Ensino n. 4, onde a FCE está instalada por enquanto. Com capacidade para 200 pessoas, as sessões têm por objetivo atrair

Tempus. Actas em Saúde Coletiva, vol. 4, n. 4, p. 149-157. 2009. 
pessoas dos movimentos sociais (contatadas pelo Eixo 1 do projeto, como visto acima), estudantes e professores/as da FCE, dos outros campi da UnB e do CEM 4, vizinhos e moradores do bairro da Guariroba (onde está localizada a FCE), jornalistas da mídia local e universitária para cobrir o evento. Neste primeiro ano do projeto, optou-se por filmes que foram produzidos na Ceilândia e/ou por seus/suas moradores/as e que retratam o processo de construção do Distrito Federal e seus meandros históricos e sociais. A cada sessão, dois/duas debatedores/as são convidados/as para, após a projeção do filme, para tecerem comentários críticos que inspirem o público ao debate. A idéia é que um/a debatedor/a seja dos movimentos sociais locais e que o/a outro/a seja da universidade. Depois, a palavra é passada ao público para que novas questões sejam levantadas. Todo o evento é filmado e, em seguida, transcrito. A idéia é, ao final do projeto, produzir um documento analítico que contemple essas falas e discussões. Desde maio de 2009, foram realizadas 7 sessões do Cine Clube. As três primeiras se realizaram no Auditório do CEM 4 e as quatro seguintes aconteceram durante a Semana de Extensão da UnB (SEMEX), no mês de setembro, com sessões ao ar livre na praça de esportes que se localiza em frente à Estação do Metrô da Guariroba:

\begin{tabular}{|c|c|c|c|}
\hline Data & Filme & Diretor/a & Debatedores/as convidados/as \\
\hline $19 / 05$ & $\begin{array}{l}\text { Rap, o canto da } \\
\text { Ceilândia }\end{array}$ & Adirlei Queiroz & Adirlei Queiroz e Eurípedes Camargo (Senador) \\
\hline $23 / 06$ & Invasores ou Excluídos & César Mendes & $\begin{array}{l}\text { Aldo Paviani (UnB), Luiz Roberto Gouvêa (UnB), Viridiano Brito } \\
\text { (ACESO), Wellington Almeida (UnB) }\end{array}$ \\
\hline $03 / 09$ & $\begin{array}{l}\text { Taguatinga em pé de } \\
\text { guerra }\end{array}$ & $\begin{array}{l}\text { Armando } \\
\text { Lacerda }\end{array}$ & $\begin{array}{l}\text { Andrea Lobo (IPEA), Flaviana Souza (PLP), Maria Madalena Torres } \\
\text { (CEPAFRE - CINE CLUBE POPULAR) }\end{array}$ \\
\hline $\begin{array}{l}\text { 29/09 } \\
\text { SEMEX/FCE }\end{array}$ & A Revolução dos Cocos & Dom Rotheroe & $\begin{array}{l}\text { Maria Madalena Torres (CEPAFRE - CINE CLUBE POPULAR), Fernando } \\
\text { Ferreira Carneiro (FCE/UnB) }\end{array}$ \\
\hline $\begin{array}{l}\text { 30/09 } \\
\text { SEMEX/FCE }\end{array}$ & $\begin{array}{l}\text { Santa Efigênia e seus } \\
\text { Pecados }\end{array}$ & $\begin{array}{l}\text { Thiago } \\
\text { Mendonça }\end{array}$ & $\begin{array}{l}\text { Maria Madalena Torres (CEPAFRE - CINE CLUBE POPULAR), Fernando } \\
\text { Ferreira Carneiro (FCE/UnB) }\end{array}$ \\
\hline $\begin{array}{l}\text { 30/09 } \\
\text { SEMEX/FCE }\end{array}$ & Semeadores da Imagem & $\begin{array}{l}\text { Juliana Marinho } \\
\text { Pires }\end{array}$ & $\begin{array}{l}\text { Maria Madalena Torres (CEPAFRE - CINE CLUBE POPULAR), Fernando } \\
\text { Ferreira Carneiro (FCE/UnB) }\end{array}$ \\
\hline $\begin{array}{l}\text { 1/10 } \\
\text { SEMEX/FCE }\end{array}$ & $\begin{array}{l}\text { "Chico Mendes" - O } \\
\text { preço da Floresta }\end{array}$ & Rodrigo Astiz & $\begin{array}{l}\text { Maria Madalena Torres (CEPAFRE - CINE CLUBE POPULAR), Fernando } \\
\text { Ferreira Carneiro (FCE/UnB) }\end{array}$ \\
\hline $\begin{array}{l}\text { 2/10 } \\
\text { SEMEX/FCE }\end{array}$ & Cinema Engenho & $\begin{array}{l}\text { Dácia Ibiapina } \\
\text { FC/UnB }\end{array}$ & $\begin{array}{l}\text { Maria Madalena Torres (CEPAFRE - CINE CLUBE POPULAR), Dácia } \\
\text { Ibiapina FC/UnB , Fernando Ferreira Carneiro (FCE/UnB), Clélia Parreira } \\
\text { FCE/UnB }\end{array}$ \\
\hline $\begin{array}{l}\text { 2/10 } \\
\text { SEMEX/FCE }\end{array}$ & $\begin{array}{l}\text { Rap, o canto da } \\
\text { Ceilândia }\end{array}$ & $\begin{array}{l}\text { Adirlei Queiroz } \\
\text { FC/UnB }\end{array}$ & $\begin{array}{l}\text { Maria Madalena Torres (CEPAFRE - CINE CLUBE POPULAR), Dácia } \\
\text { Ibiapina FC/UnB, Adirlei Queiroz }\end{array}$ \\
\hline $\begin{array}{l}16 / 11 \\
\text { Seminário }\end{array}$ & $\begin{array}{l}\text { Conterrâneos Velhos de } \\
\text { Guerra }\end{array}$ & $\begin{array}{l}\text { Wladimir } \\
\text { Carvalho }\end{array}$ & $\begin{array}{l}\text { Gustavo Lins Ribeiro ICHS/UnB, Manuel Gevan - SPPC, Eurípedes } \\
\text { Camargo (Senador) }\end{array}$ \\
\hline
\end{tabular}

Tempus. Actas em Saúde Coletiva, vol. 4, n. 4, p. 149-157. 2009. 
Nem sempre as sessões do Cine Clube contaram com um público muito numeroso. No início, as sessões eram noturnas, logo depois do expediente. Esperava-se que esse horário facilitasse que os movimentos sociais pudessem participar com mais facilidade. Mas os/as estudantes da FCE e do próprio CEM 4 tinham dificuldades de ficar. A partir de agosto, optou-se por transferir as sessões para o horário do almoço, como geralmente acontece com as mostras cinematográficas no Campus Darcy Ribeiro. Ainda assim, o Cine Clube, como mais antiga e permanente atividade cultural da FCE, ainda precisa incrementar sua audiência. Acredita-se que esse é um processo de formação progressivo.

A última sessão do Cine Clube do ano de 2009 foi realizada durante as atividades do Seminário Integrativo da FCE, uma semana no mês de novembro em que todas as atividades são suspensas para que estudantes, professores/as e técnicos/as possam se concentrar em trocar experiências acumuladas durante o semestre. Neste Seminário Integrativo foi abordado a "violência" como tema norteador e o Cine Clube deste projeto contribuiu para essa discussão ampliando seu público para 700 pessoas (com transmissão simultânea do auditório para 8 salas).

O terceiro eixo pretende transformar as idéias debatidas pelo projeto, nos contatos do Eixo 1 e nas sessões de cinema do Eixo 2, em atividades práticas e continuadas. Aqui, a expectativa é que universidade e comunidade possam planejar alguns projetos-piloto, inspirados diretamente na idéia de "ambientes saudáveis", que possam ser implantados concretamente ali mesmo na Ceilândia. A convivência e o amadurecimento político sobre as idéias do projeto nesse ano de 2009 servirão como base para o início desses projetos-piloto nos próximos meses. Um das experiências já realizadas nesse sentido foi o Trote socioambiental. Esse primeiro projeto demonstrativo teve por objetivo a implementação de práticas sustentáveis e solidárias de trote aos/às recémchegados/as novos/as estudantes. Em volta do atual campus da FCE, foram plantadas 50 mudas de árvores do cerrado (ipês e ingás) pelos/as calouros/as. Estes/as últimos/as que serão responsáveis pela manutenção das mudas com a supervisão dos/as estudantes veteranos/as. A atividade foi filmada pelos próprios/as estudantes que estão concorrendo ao Edital "Curta o Trote", do Decanato de Assuntos Comunitários da UnB, que irá selecionar os curtas metragens que retratarem as mais exitosas experiências de trote solidário. Ao final dessa atividade, ocorreu a distribuição de 500 canecas do Programa da

Tempus. Actas em Saúde Coletiva, vol. 4, n. 4, p. 149-157. 2009. 
Agenda Ambiental da UnB para os participantes da comunidade acadêmica. $O$ intuito da distribuição das canecas é a eliminação do uso de copos plásticos descartáveis, diminuindo a quantidade de lixo produzido pela FCE/UnB.

O quarto eixo pode ser entendido como uma espécie de "meta eixo" porque tem como principal objetivo ajudar na comunicação e sistematização dos demais eixos. Isso tem sido feito, por um lado, na relatoria de todas as reuniões realizadas pelo grupo, com claro intuito de preservar e socializar a memória processual dessa iniciativa. Por outro lado, este eixo se responsabiliza por produzir os materiais de divulgação do projeto. Primeiro, o projeto apelou para os efeitos midiáticos imediatos da internet. Um blog do projeto foi criado e ali se veiculavam chamados para reuniões, as sessões do cine clube, eventos paralelos e complementares ao projeto. Mas avaliou-se que dificilmente outras pessoas, que não integrantes do projeto, estavam acompanhado as notícias do blog. Optou-se por divulgar as atividades do projeto via emails do alunado da FCE e também via uma lista de discussão de emails, entre os/as participantes do projeto, estratégia muito exitosa para organizar atividades e planejar encontros. No início do projeto, tentou-se criar um jornal mensal, que teria, a princípio, circulação eletrônica. Mas a complexidade dos softwares voltados para a criação de periódicos dificultou sua utilização e o jornal ficou em um primeiro número até o momento. Em meados de 2009, surgiu a idéia de um mural físico, afixado na principal parede de circulação da FCE. O mural é constantemente atualizado com fotos das atividades, convites para as reuniões, documentos informativos etc. Assim, não só os/as membros do projeto ficam a par das atividades, como outros estudantes se atualizam também.

Este eixo possibilitou também que se aprendesse a divulgar as atividades para a mídia mais ampla, sempre na expectativa de conhecer boas e novas histórias. O projeto estreitou laços com a Secretaria de Comunicação da UnB (SECOM/UnB), a UnB TV e jornais locais da cidade, como o Correio Braziliense.

Outras atividades relacionadas ao impacto do projeto na FCE podem ser relacionadas com na Semana de Extensão da UnB (SEMEX), onde o projeto propôs oficinas, debates e reflexão. A participação do projeto na SEMEX culminou com a premiação da FCE como o campus que mais ofereceu atividades, dentre todas as unidades da UnB. O projeto também foi fundamental para a mobilização que conquistou um ônibus que irá levar 42 alunos da FCE para o IX Congresso Brasileiro de Saúde Coletiva, que acontecerá no início de novembro de 2009 na cidade do Recife. Nesta ocasião, o projeto será apresentado pela primeira vez em um evento de escala nacional.

Tempus. Actas em Saúde Coletiva, vol. 4, n. 4, p. 149-157. 2009. 


\section{ALGUNS CAMINHOS POSSÍVEIS DO PROJETO}

O projeto CASA está terminando um primeiro ciclo nesse final de 2009. Seus quatro eixos foram todos testados e continuam em permanente revisão e reciclagem. A cada novo evento, uma avaliação é feita e tenta-se incorporar aprendizados. Por enquanto, gostaríamos de registrar alguns dos efeitos que 0 projeto tem produzido em seus participantes. Embora muitas outras opiniões poderiam ser registradas aqui, especialmente das platéias do Cine Clube e também dos movimentos sociais em diálogo com o projeto, optou-se, por enquanto, por garantir a voz das pessoas que têm levado o projeto adiante, em seu dia-a-dia. Aqui, o propósito é captar algumas das transformações que o projeto tem promovido entre seus membros. Acredita-se que os resultados de um projeto, seja de extensão e/ou de pesquisa, precisam atingir, primeiramente, aqueles que nele estão envolvidos, tanto como modelo e exemplo para outros públicos, quanto como avaliação de sua eficiência e capacidade promissora.

Um dos efeitos mais rapidamente percebidos a partir desta iniciativa de extensão tem sido a transposição dos limites tradicional e simbolicamente mantidos por uma concepção mais convencional de "universidade". Aprende-se fora dos espaços corriqueiros e conhecem-se as imediações onde a universidade está situada. Diálogo é promovido entre diferentes espaços, atores e tempos. Prática e reflexão são automaticamente estimuladas.

Logo no meu primeiro semestre na universidade, fazer parte do projeto "construindo ambientes saudáveis", o primeiro projeto de extensão da UnBCeilândia, foi uma experiência inesquecível. Pois, não tinha noção do que era a extensão e da importância de se viver fora das salas de aula ou fora dos muros da universidade, repassando e multiplicando saberes. (...) A principal oportunidade que o CASA me proporcionou, foi poder conhecer e me envolver com pessoas da minha cidade, da minha quadra, da minha rua e da nossa universidade. (Lusmair Brito, Estudante do $2^{\circ}$ semestre de Fisioterapia).

O CASA vem demonstrando ser uma oportunidade única para nós enquanto alunos da instituição, onde podemos associar os conhecimentos adquiridos em nossa formação com a experiência cotidiana da comunidade local, possibilitado através do contato direto com os movimentos e a população em geral (Luciano José da Silva, Estudante do $3^{\circ}$ semestre de Gestão em Saúde Coletiva/FCE/UnB).

Tempus. Actas em Saúde Coletiva, vol. 4, n. 4, p. 149-157. 2009. 
Outro efeito perceptível e igualmente importante é o caráter coletivo da iniciativa, desde as reuniões entre os componentes do projeto ou com outros representantes da UnB (Agenda Ambiental, Decanato de Extensão etc.), até as sessões do Cine Clube. Embora os dois depoimentos que seguem se refiram ao Cine Clube, sugerimos que podem ilustrar um caráter mais abrangente e mais duradouro deste projeto. Isto é, a diversidade de opiniões e vivências como uma oportunidade de tornar mais crítica e comprometida a díade aprendizado-ação. Esta diversidade, inclusive, muitas vezes se mostra a partir de idéias polêmicas, de discordâncias e atritos, de contradições em coexistência.

Os cineclubes com os seus debates riquíssimos, dado ao fato de que esse evento aborda vários tipos de visões de mundo. As polêmicas discutidas de formas multidisciplinares. Aos poucos estou conseguindo tornar minha visão de mundo mais crítica. (Thiara Café, Estudante do $3^{\circ}$ semestre em Terapia Ocupacional/FCE/UnB).

Através da extensão podemos conhecer outros valores, opiniões, enriquecer de uma maneira muito extensiva nossa formação acadêmica, em especial nesse projeto onde o cine clube tem sido uma ferramenta valiosa, na comunicação com a comunidade, com outros profissionais, debatedores que de forma construtiva trazem diferentes olhares para os assuntos abordados, como numa colcha de retalhos. À primeira vista, os tecidos diferentes e separados parecem que não podem ser combinados, mas quando a colcha é feita, o resultando final, com essa junção de coisas, muitas vezes tão distintas, pode ser surpreendente. (Talita Maleski, Estudante do $3^{\circ}$ semestre em Terapia Ocupacional/FCE/UnB).

Em um projeto coletivo, é impossível se atomizar em uma atividade ou tarefa. Desde o início do projeto, ficou claro para todo o grupo que sua confecção dependeria da participação ativa de cada um/a. Não havia nada criado aprioristicamente. Desde o conceito de "extensão", até a definição dos "eixos" e sua execução diária, era preciso contribuir para pensarmos juntos/as. Idas e vindas, sucessos e fracassos, visões e revisões foram necessárias a cada semana do projeto. E esse mecanismo tentativamente mais horizontal, democrático e transparente, embora cause ansiedade e talvez insegurança em partícipes tão jovens e acostumados ao trabalho individual incutido pelo sistema educacional no país, foi a tônica experimentada na presente iniciativa. As lições,

Tempus. Actas em Saúde Coletiva, vol. 4, n. 4, p. 149-157. 2009. 
às vezes mínimas, às vezes grandiosas, precisam ser recuperadas e registradas como o exemplo abaixo:

Eu tive grandes aprendizados, como: falar em publico, assumir responsabilidades, trabalhar em grupo e a força desse tipo de postura. (...) E algo único que também tive oportunidade de aprender, como gestora [do projeto], foi sobre a parte burocrática, orçamentos, memorandos entre outros. (Thiara Café, Estudante do $3^{0}$ semestre em Terapia Ocupacional/FCE/UnB).

O fato de o projeto visar a convivência, cada vez mais qualificada, com a cidade que recebe e abriga a FCE, imagens negativamente cristalizadas sobre a Ceilândia têm sido desconstruídas e revistas. Freqüentar um campus na cidade e também um projeto de extensão aí radicado pode contribuir para mudar estereótipos e pensar de forma um pouco mais comparativa e diacrônica:

Como morei na Ceilândia no início dos anos 90, era bem novinha, mas lembro de ter ouvido meus pais e tios falarem da fama da cidade de ser mal vista, que era local de marginal e todos eram discriminados por ali morar. Havia nos noticiários relatos de muita violência e também a aparência da cidade não era das melhores. Neste último ano, voltei a conviver em Ceilândia, no campus da Universidade de Brasília que na cidade se instalou, como estudante também faço parte do projeto de extensão, onde estou tendo a oportunidade de conhecer a história dessa cidade. (...) Eu não fazia idéia da participação da comunidade através dos movimentos, é algo histórico e que precisa se manter, há muito que conquistar e as novas gerações não podem se acomodar. (Micheli Pereira, Estudante do $3^{\circ}$ semestre em Gestão em Saúde Coletiva /FCE/UnB).

E, ao olhar em volta do campus, ao pensar a inserção de uma unidade universitária num contexto complexo como a Ceilândia, é impossível não voltar a mirada reflexiva para o próprio ponto de partida. De forma sempre cíclica e renovada, o projeto consolida também sua origem, a Faculdade de Ceilândia:

Além disso, várias outras atividades que realizei no projeto como o trote sócio ambiental e a entrega das canecas foram muito importantes e porque não divertidas e educativas que me contribuíram para socializar ainda mais com outras pessoas e a fazer a diferença na Universidade. (Luciana Passos, Estudante do $3^{0}$ semestre de Gestão em Saúde Coletiva/FCE/UnB).

Tempus. Actas em Saúde Coletiva, vol. 4, n. 4, p. 149-157. 2009. 
A primeira coisa que eu pensei ao ingressar na universidade foi: " $E$ agora, qual é o meu papel? O que eu posso e devo fazer neste novo universo que se abre?". São tantas possibilidades, tantas oportunidades, pessoas, amizades, eventos que calouros como eu, nunca sabem pra que lado devem ir. Contudo, algo diferiu esta experiência em especial, de outras: A faculdade também é uma caloura. Tudo na FCE está no começo, estudantes aprendendo a se virar, bem como os professores. (...) Posso dizer que ser integrante do Projeto Construindo Ambientes Saudáveis tem sido enriquecedor e gratificante para mim. Não me refiro apenas à experiência acadêmica, que possui relevante valor, mas também como cidadã, visto que me debruçar sobre o histórico e realidade de uma região que é muito próxima à região que eu moro, me torna mais que uma mera conhecedora, me torna uma agente que pode ajudar a transformar realidades impostas, que são possíveis de ser transpostas. A partir deste momento, começo a compreender meu papel não somente dentro, mas também fora da UnB. (Hellen Delchova, Estudante do $2^{\circ}$ semestre em Terapia Ocupacional/FCE/UnB).

Este relato, modesto e inicial, pretendeu registrar as principais atividades realizadas até o momento pelo projeto "CASA". Para arejar e também tornar mais "fotográfico" este relato, optou-se por trazer trechos de auto-avaliações recentemente escritas por alguns/mas dos/as estudantes que participam do projeto e aqui reproduzidas, segundo seu consentimento. Aprender a trabalhar em grupo, dialogar com diferentes atores dentro e fora da universidade e, sobretudo, refletir sobre a nossa inserção no mundo - em sua dimensão planetária, mas também em sua dimensão localizada como um bairro ou uma cidade - têm sido os principais vértices de ação desse projeto. Enumerado dessa forma, essas tarefas podem parecer simples. Mas é no exercício diário de diálogo e entendimento mútuo que se realiza tais tarefas. Não se pretendeu pintar um quadro "acabado" e excessivamente harmonioso do projeto porque se entende que, como processo vivo, ele é ziguezagueantemente composto de sucessos e fragilidades, ruídos e sintonias.

Por fim, se por um lado, o CASA desafia definições mais convencionais de "extensão" historicamente ligadas a certo assistencialismo ou até um paternalismo em relação às "comunidades atendidas", igualmente são desafiadas imagens desatualizadas de "universidade". Nosso objetivo é olhar "para fora" para melhor olhar "para dentro". Entender a Ceilândia, essa grande

Tempus. Actas em Saúde Coletiva, vol. 4, n. 4, p. 149-157. 2009. 
casa que tão generosamente tem recebido a Universidade de Brasília, é um primeiro passo para arrumar nossa pequenina casa acadêmica.

Tempus. Actas em Saúde Coletiva, vol. 4, n. 4, p. 149-157. 2009. 